\title{
Studies on Occurrence, Antibiogram and Decontamination of Salmonella enterica in Table Eggs
}

\author{
C.O. Vinayananda ${ }^{1}$, Mohamed Nadeem Fairoze ${ }^{1}$, C.B. Madhavaprasad ${ }^{2}$, \\ S.M. Byre Gowda ${ }^{3}$, C.S. Nagaraj ${ }^{4}$ and Nagappa Karabasanavar ${ }^{2}$ \\ ${ }^{1}$ Department of Livestock Products and Technology, Veterinary College, Bengaluru-24, India \\ ${ }^{2}$ Department of Veterinary Public Health and Epidemiology, Veterinary College, \\ Shivamogga-04, India \\ ${ }^{3}$ IAH\&VB, Hebbal, Bengaluru -24, India \\ ${ }^{4}$ AICRP on Poultry (Meat), Veterinary College, Hebbal, Bengaluru-24, India
}

*Corresponding author

\begin{tabular}{|l|}
\hline K e y w o r d s \\
Occurrence; \\
$\begin{array}{l}\text { Salmonella; eggs; } \\
\text { isolation; PCR; } \\
\text { antibiotics, } \\
\text { decontamination. }\end{array}$ \\
\hline Article Info \\
\hline $\begin{array}{l}\text { Accepted: } \\
\text { 20 February } 2017 \\
\text { Available Online: } \\
\text { 10 March 2017 }\end{array}$ \\
\hline
\end{tabular}

Keywords

Occurrence

Salmonella; eggs;

antibiotics,

decontamination

\section{A B S T R A C T}

Salmonellosis is one of the major leading foodborne zoonotic diseases reported worldwide, poultry and poultry products including table eggs were reported as the most important source for foodborne outbreaks in humans. The present study was designed to determine and compare the occurrence of Salmonella serovars by cultural and molecular (PCR) methods in processed, unprocessed and desi table eggs available in the markets, resistance pattern of isolates for commonly used antibiotics and decontamination of table eggs using chlorine and peracetic acid. The results of present study revealed that occurrence of Sal. Enteric was found to be 5.95 and 9.52 per cent by cultural and PCR method, respectively.Among the isolates obtained, 3.57 per cent was found to be $S$. enteritidis and 2.38 per cent of was $S$. typhimurium serotypes. The occurrence of $S$. enterica was found to be $2.08,8.33$ and 16.67 per cent in processed, unprocessed and desi table eggs, respectively. The MAR indices for all five isolates Salmonella enterica was 0.2.Considering the reduction of TVC and Salmonella counts from the table egg surface after sanitation, $100 \mathrm{ppm}$ of per acetic acid (PAA) as a sanitizer was comparatively effective than $200 \mathrm{ppm}$ of chlorine (CL). Higher occurrence of Salmonella species in the egg is of great public health concern. The study further reinforces the necessity of improving the table eggs before it reaches the consumer.

\section{Introduction}

Eggs are one of the economical nutritious food items from the livestock and they form an important part of the routine human diet. However, good qualities of nutrients in eggs offer the suitable environment to the microbial proliferation. Eggs can be contaminated or infected horizontally (through the shell) or vertically (transovarially), that may become potential source of foodborne diseases in humans (Martelli and Davies, 2011). Some 
pathogens like Salmonella, Escherichia coli, Camphylobacter spp and enterococcci may vertical transmitted (Sreenivasaiah, 2006). Others sources of contamination are through poultry workers, houses or cage, handling during transportation and marketing. Among the egg borne disease Salmonellosis is a major leading disease worldwide. Salmonella enteritidis and Salmonella typhimurium are the two most important serotypes of Salmonella transmitted from animals to human beings. Along with the gastroenteritis they also cause extra intestinal diseases like pleural empyema, meningitis, splenic abscess, meningitis, pleural effusion and osteomyelitis (Sudhaharan et al., 2014). Salmonella enterica is a Gram-negative rod-shaped non spore-forming bacterium (Pui et al., 2011). There are around 2,500 known Salmonellae serotypes have been documented of which 209 serovars were reported in India (Rahman, 2002). Most commonly used technique for Salmonella detection is the conventional or cultural technique and serological tests which are time consuming and labor intensive. Alternatively, PCR technology is employed which is a rapid method with high sensitivity and specificity.

In order to achieve the objective of food safety in modern egg production and processing, sanitization of eggs has become a common practice. Several sanitizers are used for this purpose, such as chlorine (Favier et al., 2001), hydrogen peroxide (Padron, 1995); electrolyzed water (Deza et al., 2003; David et al., 2006; Subrota et al., 2012), UV radiation (Kuo et al., 1997), pulsed light, ozone (Whistler and Sheldon, 1988); gaseous plasma (Luigi et al, 2010) etc., keeping relative merits and limitations in view, chlorine has emerged as one of the best sanitizers used for egg sanitization (Favier et al., 2001). Chlorine exerts its germicidal property by penetrating into the bacterial cell wall; it interferes with sulfhydril containing enzymes of glucose metabolism thereby leading to death of bacteria (Banwart, 1979). Similarly per acetic acid also has shown better effect in reducing the bacterial load on food material and also has effective antimicrobial activity in presence of organic matter compared to chlorine (Cruz et al., 2007). Per acetic acid is most commonly used in food processing and handling, sanitizer for food contact surfaces and as a disinfectant for fruits, vegetables, meats, and eggs. It is approved by FDA for use as an indirect food additive (FDA, 2005). So, in the present study peracetic acid is compared with the efficacy chlorine against decontamination of table eggs inoculated with the Salmonella Typhimurim isolates.

Table eggs available in the Indian markets were from commercial layer farms and poultry reared in backyard. Portion of eggs from commercial or integrated layer farms which layers are processed, packed and marketed under different brand names (processed) and maximum portion of eggs are marketed through wholesalers/retailers without any brand names (unprocessed). Therefore, in the present study an attempt has been made to determine the occurrence of Salmonella serotypes by cultural and PCR methods in the different groups table eggs, antimicrobial resistance pattern of the isolates and comparison of efficacy of PAA (100ppm) with the CL (200ppm) for surface decontamination of table eggs.

\section{Materials and Methods}

A total of 840 table egg samples were collected from retail markets of selected districts from Karnataka, India. The samples were collected in a sterile plastic bag and immediately transported to the laboratory. In the present study eggs were categorized into 3 groups, which comprised of processed (480 
eggs of 4 different brands- 120 eggs from each brand), unprocessed (240 eggs) and desi eggs (120 eggs). All these egg samples (10 eggs per sample) were analysed for occurrence of Salmonella enterica in egg contents. The samples were collected and analysed at four occasions with an interval of 15 days.

\section{Preparation of sample}

Ten eggs were selected from each batch and egg surface was sterilized by using $70 \%$ ethanol. Then the eggs were broken into a sterile polythene bag. The bags were subjected to homogenization in stomacher (BAG MIXER ${ }^{\circledR}$, Interscience) for 2 min to obtain a uniform homogenate.

\section{Occurrence of Salmonella enteric by cultural methods}

Standard method of isolation of Salmonella i.e. ISO 6579:2002 was followed in this study. The isolation step involved four stages, non-selective pre-enrichment (buffered peptone water -BPW), selective enrichment (Rappaport-Vassiliadis broth), selective plating (Xylose Lysine Deoxycholate-XLD) and confirmation of Salmonella suspected isolates by morphology, motility, biochemical tests and for molecular characterization of isolates, DNA was extracted in the present study by Snap-chill method (Zahrei et al., 2005) followed by determination of virulence markers based on specific amplification of invA gene by polymerase chain reaction (PCR) (Rahn et al., 1992). The nucleotide sequences of the forward and reverse amplimers were 5'-GTG AAA TTA TCG CCA CGT TCG GGC AA -3' and 5'-TCA TCG CAC CGT CAA AGG AAC C -3', respectively with amplicon size of $284 \mathrm{bp}$. Samples were amplified with temperature conditions consisted of an initial $95^{\circ} \mathrm{C}$ denaturation step for 1 min followed by 35 cycles, with each cycle consisting of $1 \mathrm{~min}$ at $94^{\circ} \mathrm{C}$ for denaturation, $1 \mathrm{~min}$ at $64{ }^{\circ} \mathrm{C}$ for primer annealing, $0.5 \mathrm{~min}$ at $72^{\circ} \mathrm{C}$ for strand elongation and the final cycle at $72^{\circ} \mathrm{C}$ for 7 min.. PCR products were visualized following electrophoresis through $1.5 \%$ agarose gels stained with ethidium bromide.

\section{Electrophoresis}

Agarose gel (1.5\%) was prepared by heating molecular biology grade agarose in $1 \mathrm{X} \mathrm{TAE}$ (Tris Acetate EDTA) buffer so as to dissolve it completely. After cooling to about $50{ }^{\circ} \mathrm{C}$, ethidium bromide $\left(\mathrm{C}_{21} \mathrm{H}_{2} \mathrm{OBrN}_{3}\right)$ was added to a final concentration of $1 \mu \mathrm{g} / \mathrm{mL}$. Molten agarose was then poured into the gel-casting unit and kept undisturbed. After solidification, the comb was removed from the gel. The set gel along with gel-casting unit was submerged in electrophoresis buffer (TAE, 1X). About $4 \mu \mathrm{l}$ of PCR product was mixed with $1 \mu \mathrm{l}$ of gel loading dye-6X (10 mMTris- $\mathrm{HCl}$ (pH 7.6) $0.03 \%$ bromophenol blue, $0.03 \%$ xylene, cyanol FF, $60 \%$ glycerol $60 \mathrm{mM}$ EDTA) and loaded into the wells using long micro pipette tips. Simultaneously 100 bp/50bp DNA molecular weight markers were also loaded in one of the wells and electrophoresis was performed at 70 Volts. The progress of mobility was monitored by viewing migration of the dye front. After electrophoresis, the gel was visualized under UV trans-illuminator and gel image was photographed.

\section{Serotyping of Salmonella enterica}

Sal.enterica isolates that showed positive reactions in biochemical and sugar fermentation tests were further employed for serotyping. All the Sal. entericisolates were sent to National Salmonella and Escherichia Centre, Central Research Institute, Kasauli 
(Himachal Pradesh) for serotyping.

\section{Occurrence of Salmonella enterica by PCR method}

$2 \mathrm{ml}$ of the pre-enriched samples were centrifuged at $6,000 \mathrm{rpm}$ for $10 \mathrm{~min}$ and pellet of the bacterial cells obtained. Pellet was washed with sterile phosphate buffered saline (PBS; pH 7.4) once. The pellet was resuspended in $50 \mu \mathrm{l}$ of nuclease free water and kept in a boiling water bath at $100{ }^{\circ} \mathrm{C}$ for10 min, then transferred immediately to freezer at $(-20){ }^{\circ} \mathrm{C}$ for $15 \mathrm{~min}$. After freezing, the suspension was centrifuged again at $6,000 \mathrm{rpm}$ for $10 \mathrm{~min}$. The supernatant was collected and used as template DNA for PCR assay (Manoj et al, 2014). PCR products were visualized following electrophoresis through $1.5 \%$ agarose gels stained with ethidium bromide and the amplicons were identified based only on the size of the amplified product as explained in paragraph 2.2 .

\section{Antibiogram of $S$. enteric isolates}

Antimicrobial susceptibility testing was performed by using Kirby-Bauer's disc diffusion method (Bauer et al., 1966) as described by Clinical and Laboratory Standards Institute (CLSI, 2012). All the isolates were tested against 15 antibiotics using antibiotic discs procured from M/s. HiMedia $^{\circledR}$ Ltd., Mumbai. The list of antibiotic discs used and their concentration is given in the Table 2 Multiple Antibiotic Resistance (MAR) index was calculated for each of the isolates obtained to study the spread of antibiotic resistance as described by Kruperman (1983).

\section{Decontamination of table eggs}

In the present study 100ppm of PAA and 200ppm CL were selected for sanitary trials against artificially inoculated $S$. typhimurium on table eggs. Commercially available chlorine tablet $\left(\mathrm{M} / \mathrm{s}\right.$. $\left.\mathrm{NICE}^{\circledR}\right)$ with the available chlorine of $60 \%$ and PAA (peracetic acid-5\%, hydrogen peroxide- $15 \%$ and acetic acid $10 \%$ ) used in the present study. The effective concentration of sanitizers and contact time was selected based on the invitro studies.

\section{In-vitro study}

Efficacy of CL and PAA of different concentrations (i.e., 40, 80, 120, 160 and 200 ppm of CL and 10, 50, 70, 100 and 200ppm of PAA) on $S$. typhimurium at desired concentrations from $10^{1}$ to $10^{10} \mathrm{cfu} / \mathrm{ml}$ was determined at 3 different contact time ie., 1, 2.5 and $5 \mathrm{~min}$. The results obtained in the study showed that $200 \mathrm{ppm}$ of CL and 100 ppm of PAA was more effective on the $S$. typhimurium and TVC at the contact time of $2.5 \min$

\section{Experimental design for sanitary trials on table eggs}

A total of 36 clean and good quality table eggs were collected from the market and used in the experiment. Egg candling was done to remove the cracked and poor shelled eggs. All eggs disinfected with the 70 per cent alcohol. Samples divided into 4 groups with 3 eggs in each group. Groups were divided as a positive control (inoculated), negative control (without inoculated) and 2 test groups each for chlorine and PAA. The trials had been carried out in triplicates. The inoculum was prepared by adding2-3 S. typhimurium colonies from Xylose Lysine Deoxycholate Agar plate into $10 \mathrm{ml}$ of peptone water and incubated at 37 ${ }^{\circ} \mathrm{C}$ for 24 hours. The 24 hour culture was further diluted to required quantity in the ratio of $1: 10$, so that final concentration of inoculum was approximately $10^{8} \mathrm{cfu} / \mathrm{ml}$ and used for surface inoculation.

A $500 \mathrm{ml}$ sterile beaker was taken to which 30 
$\mathrm{ml}$ of each of fresh culture of $S$. typhimurium (i.e. age of the culture was 24 hours) grown in peptone broth was poured and $270 \mathrm{ml}$ of sterile peptone water was added in order to get a $\log$ dilution of $1: 10$ and thus $300 \mathrm{ml}$ of total volume of the culture was prepared. The table eggs were immersed in the culture for about $10 \mathrm{sec}$, transferred into the sterile plastic pouches and allowed to be dried for 30 min.

\section{Application of sanitizers to table eggs for decontamination}

200 ppm of CL and 100 ppm of PAA were freshly prepared using chlorine free sterile water used in the study. The inoculated table eggs completely immersed in the respective sanitizer (i.e., $200 \mathrm{ppm}$ of CL or $100 \mathrm{ppm}$ PAA) for an effective contact time of 2.5min.After that immediately transferred into the $100 \mathrm{ml}$ of 0.1 per cent peptone water to terminate the effect of sanitizer, this rinset was used to estimate the TVC and $S$. typhimurium count

\section{Determination of efficacy of sanitizers}

The efficacy of the sanitizers for decontamination of eggs determinedin terms of total viable count (TVC) and recovery of $S$. typhimurium from the surface of table eggs after decontamination. Spread plate technique was employed to determine the TVC. $0.1 \mathrm{ml}$ of rinset from treatment and control groups were inoculated on the respective plates and incubated at $37{ }^{\circ} \mathrm{C}$ for $24-48$ hours followed by recoding the TVC (cfu/ml) after completion of the incubation period.

The recovery of viable $S$. typhimurium was carried out as per the ISO 6579:2002, as explained in paragraph 2.2.Plates were observed for growth of $S$. typhimurium and counts of the organism were enumerated and the $\log$ reduction values were derived.

\section{Statistical analysis}

Statistical analysis was carried out using MS Excel-2010 and SPSS v20.

\section{Results and Discussion}

The present study revealed that, 5.95 per cent of the samples were positive for the presence of Sal. Enteric by cultural method. The occurrence of Sal. enterica in the processed, unprocessed and desi table eggs were found to be $2.08,8.33$ and 16.67 per cent, respectively.

The biochemical, molecular profiles and serotyping results of S.enterica isolates serotyped at National Salmonella and Escherichia Centre, Central Research Institute, Kasauli (Himachal Pradesh) are presented in the Table1.

Occurrence of Salmonella enterica in the table egg samples by PCR technique found to be 9.52 per cent. The occurrence of Sal. enterica in the processed, unprocessed and desi table eggs were found to be 2.08, 12.5 and 33.33 per cent, respectively by PCR methods. The results of kappa test had showed the strength of agreement between the tests for Sal. Enterica was good (0.751 \pm $0.17)$.

\section{Antibiogram and MAR indices of Salmonella enterica Isolates}

All the isolates of $S$. enterica $(n=5)$ were sensitive $(100 \%)$ to ten antibiotics viz. ampicillin, gentamicin, chloramphenicol, cefotaxime, ciprofloxacin, co-trimoxazole, tetracycline, ceftriaxone/tazobactam, nalidixic acid and streptomycin. Varying levels of sensitivity was noticed for neomycin $(60 \%)$, cefadroxil $(80 \%)$ and cephoxitin (60\%) among the different isolates of S.enterica (Table 2).All the isolates of S.enterica $(n=5)$ were resistant $(100 \%)$ to cloxacillin and 
lincomycin and only one isolate $(n=1)$ showed resistance for neomycin $(20 \%)$. Some of the isolates showed intermediate resistance for neomycin $(20 \%)$, cefadroxil $(20 \%)$ and cephoxitin $(40 \%)$. Isolates of S.enterica from processed, unprocessed and desi eggs showed 100 per cent resistance to cloxacillin and lincomycin. But for neomycin, isolates of processed and desi egg showed 100 and 50 per cent resistance, respectively. Isolates of unprocessed and desi eggs showed 50 per cent resistance to cephoxitin. All isolates of S.enterica from processed, unprocessed and desi eggs were equally sensitive to other antibiotics used in the present study. All (five) isolates of S.enterica showed the MAR indices of 0.2 .

Efficacy of sanitizers against artificially inoculated $S$. typimurium and total viable count (TVC) on surface of shell eggs

The effect of sanitizers on total viable count (TVC) assessed and it was observedthat the average counts reduced to 3.89 and $3.69 \mathrm{log}$ $\mathrm{cfu} / \mathrm{ml}$ from an initial count of $6.27 \mathrm{log} \mathrm{cfu} / \mathrm{ml}$ after treatment with $200 \mathrm{ppm}$ of CL and 100 ppm of PAA, respectively. The average log reductions for $200 \mathrm{ppm}$ of CL and $100 \mathrm{ppm}$ of PAA were recorded as $2.38(37.73 \%)$ and $2.58(41.15 \%) \quad \log \mathrm{cfu} / \mathrm{ml}$, respectively. However, the percentage of log reductions was found to be better for 100 ppm of PAA than $200 \mathrm{ppm}$ of CL in the present study. Likewise, the average initial inoculation (positive control) counts for the $S$. typhimurium on the surface of table eggs was found to be $4.29 \mathrm{log}$ $\mathrm{cfu} / \mathrm{ml}$ after sanitation achieved 100 per cent reduction $S$. typhimurium from the surface of table eggs. The results of sanitary trials were subjected to statistical analysis and it revealed that both the sanitizers were found to be significantly $(\mathrm{P}<0.05)$ effective in reducing the initial TVC.

The table eggs produced and marketed might vary in their qualities from very good to very poor quality attributes in terms of microbial load. Some pathogens may occasionally present within the egg at the time of lay, but much more commonly it contaminates the liquid egg from the external surface of the shell during storage by penetration or during breaking of the shell. Among the egg borne pathogens Salmonellae is one of the commonly isolated which is more pathogenic and transmitted both vertically as well as horizontally. InvA gene target was most commonly used for the detection of Salmonella in PCR assays (Itoh et al., 1997; Makino et al., 1999 and Wolffs et al., 2006). However, researchers have also reported characterization/detection of Salmonella by targeting other genes such as $r f b E$, fliC, virA, spvC, in $T$ and $f l O$ (Itoh et al., 1997; Haqueet al., 1999; Khan et al., 2000 and Woo et al., 2001, Goelet al., 2013).

The present study revealed 100 per cent concordance of cultural detection with respect to invA gene based on PCR for Sal. enterica which were isolated from the table egg samples. Since invasion gene is associated with the pathogenicity or virulence of the $S$. enterica, presence of 284 bp invA gene amplicon suggested the occurrence of potentially pathogenic determinants in all the five isolates recovered from table eggs collected from markets. Martelli and Davies (2011) reported that $S$. enteritidis appears to play a major role in egg contamination. $S$.enteritidis was more frequently isolated than $S$. typhimurium from table eggs and these observations are in agreement with the results of present study. The results of the present study is supported by the research of several workers, (Adesiyun et al., 2005; Nagappa et al., 2006; Madhavaprasad, 2009; Assefa et al., 2011; Gole et al., 2013) in a study conducted on quality and safety of raw shell eggs. But, Al-Obaidi et al., (2011) found that higher occurrence of Salmonella i.e., 20.0 per cent in table eggs collected from retail stores in 
Baghdad and 38.7 per cent in imported eggs, Paul et al., (2016) reported the isolation rate of salmonella was 1.97 percent. In contrary, Safaei et al., (2011) reported zero per cent occurrence of Salmonella in table eggs collected from the local markets of Iran.

This study compared the occurrence of Salmonella enteric by molecular method i.e., PCR and the conventional culture methods in table egg samples. Most research attempts to establish a method, which can reduce the time required for detection of Sal. Enteric from various samples including table eggs (Oliveira et al., 2002; Malorny et al., 2004; Kiranmayi and Krishnainh, 2010). Sensitivity and specificity of PCR is more than cultural methods (Loongyai et al., 2011; Manoj et al., 2014).

In the recent years, there has been a drastic increase in the incidence of drug resistance due to extensive and indiscriminate use of antimicrobial agents for prophylaxis or for growth promotion. The emergence of drug resistant strains follows continued feeding of antimicrobials to layers (Smith and Hall, 1966; Singh et al., 1992). Results of antibiogram in the present study were similar to results reported by Nicodim et al., (2011). In contrary Hassan et al., (2014) reported that isolates of Sal.enterica were 100 per cent sensitive to neomycin. Ahmed et al., (2011) reported similar sensitivity pattern $(100 \%)$ for chloramphenicol, ampicillin and nalidixic acid against S.enterica isolates. Many Salmonella isolates exhibited resistance to tetracycline (63.4\%), nalidixic acid (63.4\%), and streptomycin (61.0\%) (Musgrove et al., 2006). The antimicrobial resistance patterns of Salmonella vary depending upon the time, region, serovar, the farm practices, breeds and the frequency of antimicrobial agent used (Gyles, 2008). Now a day, wide spread use of antibiotics in poultry production systems is contributing significantly to the increased antibiotic resistance among the Salmonella. The result of present study showed varying degree of resistance to many of the commonly used antibiotics which implies public health concern.

Several researchers have carried out experiments to determine the efficacy of disinfection of table eggs by employing different marker organisms and application of physical or chemical means of disinfection. This study is in accordance with Musgrove et al., (2006) and Favier et al., (2001) who tested the efficacy of $100 \mathrm{ppm}$ of chlorine and found that it was highly effective in reducing of mesophilic aerobic bacteria as at the rate of 45 log cfu/egg. Madhavprasad (2009) also reported 62.32 percent reduction of TVC when eggs were treated with $200 \mathrm{ppm}$ of chlorine. Masson (1990) revealed that $2 \mathrm{log} \mathrm{cfu} / \mathrm{ml}$ reductions in total counts and faecal coliforms on cutsalad mixtures were observed after treatment with $90 \mathrm{ppm}$ of peroxyacetic (peracetic) acid or with $100 \mathrm{ppm}$ of chlorine. Sella et al., (2012) conducted a study to validate the use of peracetic acid as sporicide and reported that the range of MICs was 0.61.1 per cent for the control and 0.003-0.006 per cent for the 0.2 per cent peracetic acid solution. Craig and Christine (2014) conducted several experiments to compare the effectiveness of eggshell disinfectants used in the egg industry viz., peracetic acid (PAA), PAA in combination with UV light, and $\mathrm{H}_{2} \mathrm{O}_{2}$ in combination with UV light; they also reported that peracetic acid was more effective than chlorine but less effective than QAC.In the present study, considering the reduction of TVC and pathogens from the table egg surface after sanitation by $200 \mathrm{ppm}$ of chlorine and $100 \mathrm{ppm}$ of peracetic acid, $100 \mathrm{ppm}$ of peracetic acid as a sanitizer found to be effective than $200 \mathrm{ppm}$ of chlorine as it was able to reduce both TVC and pathogen effectively. 
Table.1 Results of biochemical reactions, PCR confirmation and serotyping of Salmonella enterica isolates

\begin{tabular}{|c|c|c|c|c|c|c|c|c|c|c|c|c|c|c|c|c|c|c|c|c|c|c|}
\hline \multirow[b]{2}{*}{$\begin{array}{l}\dot{z} \\
\dot{\text { मे }}\end{array}$} & \multirow{2}{*}{ 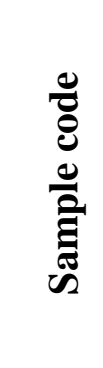 } & \multirow{2}{*}{ 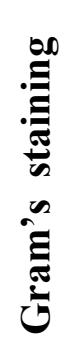 } & \multirow{2}{*}{ 泀 } & \multirow[b]{2}{*}{$\frac{\frac{0}{o}}{\mathfrak{g}}$} & \multirow[b]{2}{*}{$\stackrel{\underline{\mu}}{\Sigma}$} & \multirow[b]{2}{*}{$\frac{1}{2}$} & \multirow[b]{2}{*}{ } & \multirow{2}{*}{ 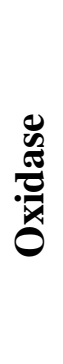 } & \multirow{2}{*}{ 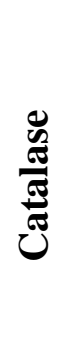 } & \multirow{2}{*}{ 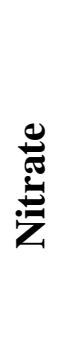 } & \multicolumn{5}{|c|}{ Triple sugar iron } & \multirow[b]{2}{*}{ 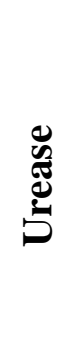 } & \multirow[b]{2}{*}{$\begin{array}{l}\vdots \\
\frac{1}{0}\end{array}$} & \multicolumn{3}{|c|}{$\begin{array}{c}\text { Sugar } \\
\text { fermentation }\end{array}$} & \multirow{2}{*}{ 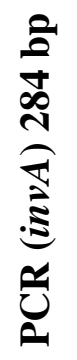 } & \multirow[b]{2}{*}{ Serotypes } \\
\hline & & & & & & & & & & & $\frac{\vec{\Xi}}{\widetilde{E}}$ & $\bar{\Xi}_{\bar{\theta}}$ & 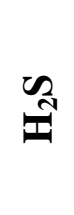 & ڤี & $\bar{\sigma}$ & & & 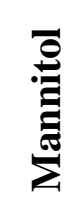 & 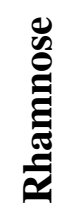 & 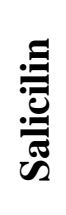 & & \\
\hline 2 & $\begin{array}{c}\text { UB2- } \\
\text { J }\end{array}$ & - & + & - & + & - & + & - & + & - & $\mathrm{K}$ & A & + & + & + & - & - & + & + & - & + & $\begin{array}{l}\text { S.enteritidis } \\
(9,12: \mathrm{g}, \mathrm{m}:-)\end{array}$ \\
\hline 3 & $\begin{array}{c}\text { UB2- } \\
\text { G }\end{array}$ & - & + & - & + & - & + & - & + & - & $\mathrm{K}$ & A & + & + & + & - & - & + & + & - & + & $\begin{array}{l}\text { S.enteritidis } \\
(9,12: \mathrm{g}, \mathrm{m:}:-)\end{array}$ \\
\hline 4 & $\begin{array}{c}\text { DS- } \\
\mathrm{H}\end{array}$ & - & + & - & + & - & + & - & + & - & $\mathrm{K}$ & A & + & + & + & - & - & + & + & - & + & $\begin{array}{c}\text { S.typhimurium } \\
(4,12: \mathrm{i}: 1,2)\end{array}$ \\
\hline
\end{tabular}

Note: K-Alkaline, A-Acidic, S-Slant, B-Butt, $\mathrm{H}_{2} \mathrm{~S}-\mathrm{Hydrogen}$ sulphide, (+) -Positive reaction; (-) - Negative reaction. 
Table.2 Antibiogram and antimicrobial resistance pattern of Salmonell aenterica isolates of processed, unprocessed and desi eggs

\begin{tabular}{|c|c|c|c|c|c|c|c|c|c|c|c|c|c|c|}
\hline \multirow{3}{*}{$\begin{array}{l}\text { Sl. } \\
\text { No. }\end{array}$} & \multirow{3}{*}{ Antibiotic } & \multirow{3}{*}{$\begin{array}{c}\text { Code- } \\
\text { content } \\
(\mu \mathrm{g})\end{array}$} & \multicolumn{6}{|c|}{ Antibiogram } & \multicolumn{6}{|c|}{$\begin{array}{l}\text { Source wise antibiotic } \\
\text { resistance pattern }\end{array}$} \\
\hline & & & \multicolumn{2}{|c|}{$\mathbf{S}$} & \multicolumn{2}{|c|}{ I } & \multicolumn{2}{|c|}{$\mathbf{R}$} & \multicolumn{2}{|c|}{$\begin{array}{c}\mathbf{P} \\
(\mathrm{n}=1)\end{array}$} & \multicolumn{2}{|c|}{$\mathbf{U P}(n=2)$} & \multicolumn{2}{|c|}{$\begin{array}{c}\text { DS } \\
(\mathrm{n}=2)\end{array}$} \\
\hline & & & $\mathbf{N}$ & $\%$ & $\mathbf{N}$ & $\%$ & $\mathbf{N}$ & $\%$ & $\mathbf{N}$ & $\%$ & $\mathbf{N}$ & $\%$ & $\mathbf{N}$ & $\%$ \\
\hline 1 & Ampicillin & A-10 & 5 & 100 & 0 & 0 & 0 & 0 & 0 & 0.0 & 0 & 0.0 & 0 & 0.0 \\
\hline 2 & Gentamicin & GEN-10 & 5 & 100 & 0 & 0 & 0 & 0 & 0 & 0.0 & 0 & 0.0 & 0 & 0.0 \\
\hline 3 & Chloramphenicol & C-30 & 5 & 100 & 0 & 0 & 0 & 0 & 0 & 0.0 & 0 & 0.0 & 0 & 0.0 \\
\hline 4 & Cefotaxime & CTX-30 & 5 & 100 & 0 & 0 & 0 & 0 & 0 & 0.0 & 0 & 0.0 & 0 & 0.0 \\
\hline 5 & Ciprofloxacin & CIP-5 & 5 & 100 & 0 & 0 & 0 & 0 & 0 & 0.0 & 0 & 0.0 & 0 & 0.0 \\
\hline 6 & Co-trimoxazole & COT-25 & 5 & 100 & 0 & 0 & 0 & 0 & 0 & 0.0 & 0 & 0.0 & 0 & 0.0 \\
\hline 7 & Cloxacillin & CX-1 & 0 & 0 & 0 & 0 & 5 & 100 & 1 & 100 & 2 & 100 & 2 & 100 \\
\hline 8 & Neomycin & $\mathrm{N}-30$ & 3 & 60 & 1 & 20 & 1 & 20 & 1 & 100 & 0 & 0.0 & 1 & 50 \\
\hline 9 & Tetracycline & $\mathrm{T}-30$ & 5 & 100 & 0 & 0 & 0 & 0 & 0 & 0.0 & 0 & 0.0 & 0 & 0.0 \\
\hline 10 & $\begin{array}{l}\text { Ceftriaxone/ } \\
\text { Tazobactam }\end{array}$ & $\begin{array}{l}\text { CIT/Tz- } \\
30 / 10\end{array}$ & 5 & 100 & 0 & 0 & 0 & 0 & 0 & 0.0 & 0 & 0.0 & 0 & 0.0 \\
\hline 11 & Cefadroxil & CFR-30 & 4 & 80 & 1 & 20 & 0 & 0 & 0 & 0.0 & 1 & 50 & 0 & 0.0 \\
\hline 12 & Nalidixic acid & NA-30 & 5 & 100 & 0 & 0 & 0 & 0 & 0 & 0.0 & 0 & 0.0 & 0 & 0.0 \\
\hline 13 & Streptomycin & S-10 & 5 & 100 & 0 & 0 & 0 & 0 & 0 & 0.0 & 0 & 0.0 & 0 & 0.0 \\
\hline 14 & Cephoxitin & $\mathrm{CN}-30$ & 3 & 60 & 2 & 40 & 0 & 0 & 0 & 0.0 & 1 & 50 & 1 & 50 \\
\hline 15 & Lincomycin & L-15 & 0 & 0 & 0 & 0 & 5 & 100 & 1 & 100 & 2 & 100 & 2 & 100 \\
\hline
\end{tabular}

M- 100 bpladder,S- Sal.Enteritidis (ATCC 13076), Lane 1:B2-K, Lane 2:UB2-J, Lane3:UB2-G, Lane 4:DS-H, Lane 5:DS-I and Lane 6- NTC.

Fig.1 Polymerase chain reaction (PCR) - amplification of invAgene (284 bp) of Salmonella isolates

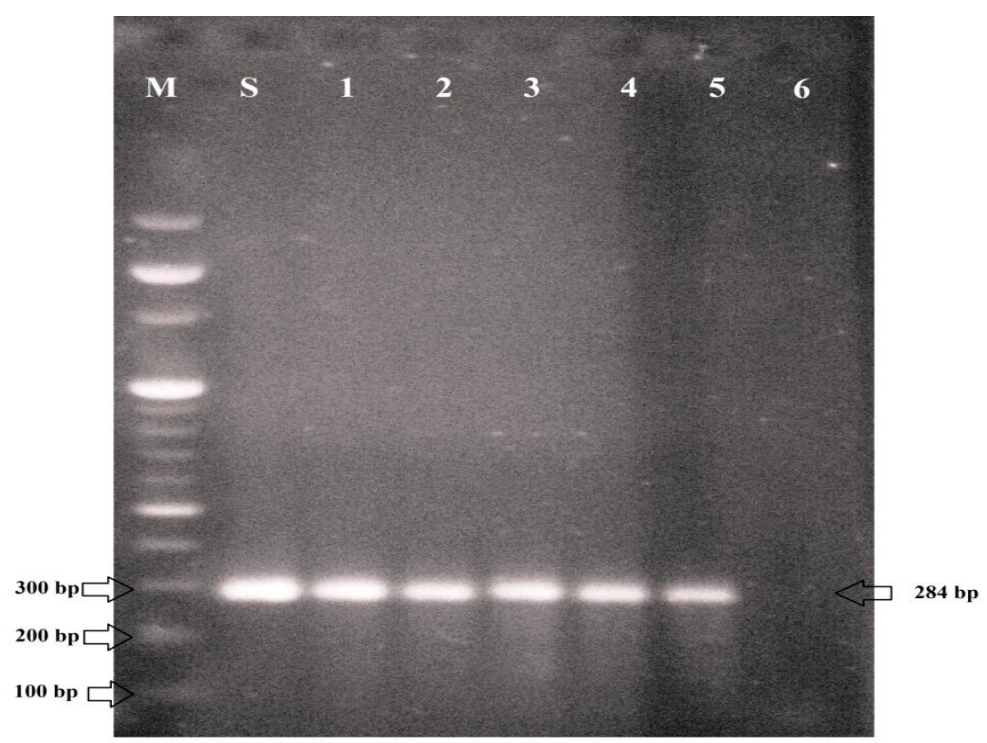

Note: R - Resistant, I - Intermediate, S- Sensitive; P: Processed; UP: Unprocessed; DS: Desi; N-Number of isolates showed resistance 
In conclusion, Salmonella enterica from layers appeared to be major biosecurity concern in the processed, unprocessed and desi table eggs, which requires sound farm based control measures to ensure safety of table eggs and also constituted a safety concern for consumers, producers and traders. The profile of resistance towards antibiotics reflected the usage of selected antibiotics in different system of the egg production practices. The results of sanitary trials obtained in this study showed that PAA was effective against Sal. Enteric as well as TV Con the exterior of shell eggs. Thus, sanitation of eggs immediately prior to breaking should materially reduce contamination of the resultant liquid egg products by microorganisms, especially gram negative bacteria, found on the shell surface. So there is need of proper care in the production practices to produce pathogenic Sal. Enteric free eggs and the use of antibiotics should be appropriate so that the wholesome eggs are produced and reaches the consumer.

\section{Acknowledgement}

Authors are thankful for Departments of Livestock Products Technology, Veterinary College Bengaluru and Veterinary Public Health \& Epidemiology, Veterinary College Shivamogga, Karnataka Veterinary Animal Fisheries Sciences University, Bidar, Karnataka (INDIA) for providing necessary facilities to carry out this work.

\section{References}

Adesiyun, A., Offiah, N., Lashley, V., Seepersadsingh, S., Rodrigo, Georges, K., 2005. Prevalence of antimicrobial residues in table eggs in Trinidad. $J$. Food Protect., 68(7):1501-1505.

Ahmed, M.M., Rahman, M.M., Mahbub, K.R., Wahiduzzaman, M. 2011. Characterization of Antibiotic Resistant
Salmonella sppIsolated from Chicken Eggs of Dhaka City. J. Sci. Res., 3(1): 191-196.

Al-Obaidi, F. A., Al-Shadeedi, S. M. J., AlDalawi, R. H., 2011. Quality, chemical and microbial characteristics of table eggs at retail stores in baghdad. Int. j. of Poult Sci., 10(5): 381-385.

Assefa, M., Teklu, A., Negussie, H., 2011. The prevalence and public health importance of Salmonella from chicken table eggs, Ethiopia. Am $J$ Agric Environ Sci., 11(4): 512-518.

Banwart, G.J. 1979. In "Basic Food Microbiology", 1st Edn. AVI Publication. Co. Inc., Westport, Conneticut, USA.

Bauer, A.W., Kirby, W.M., Sherris, J.C., Turck, M. $1966 . \quad$ Antibiotic susceptibility testing by a standardized single disk method. Am. J. Clin. Pathol., 36: 493-496.

Clinical Laboratory Standards Institute. 2012. Performance standards for the antimicrobial disc susceptibility tests. CLSI document, 32(3): M100-S22.

Craig, C. andChristine, A. 2014. Researchers evaluate shell egg sanitization practices. Poultry world, 1059.

Cruz Saúl Ruiz., EveliaAcedo-Félix., Martha Díaz-Cinco., Maria, A., Islas-Osuna., Gustavo, A. and González-Aguilar, 2007. Efficacy of sanitizers in reducing Escherichia coli O157:H7, Salmonella spp. and Listeria monocytogenes populations on fresh-cut carrots. Food control, 18(11): 1383-1390.

Favier, G.I., Escudero, M.E. and D.E. Guzman. 2001. Effect of chlorine, sodium chloride, trisodium phosphate and ultraviolet radiation on the reduction of Yersinia enterocolitica and mesophilic aerobic bacteria from eggshell surface. J. Food Protection, 64(10):1621-1623.

FDA. 2005. National Organic Program 
(NOP): Proposed Amendments to the National List of Allowed and Prohibited Substances (Crops and Processing): Federal Register, 70:179.

Gole, V.C., Chousalkar, K.K., and Roberts, J.R., 2013. Survey of Enterobacteriaceae contamination of table eggs collected from layer flocks in Australia. Int. J. Food Microbiol., 164(2-3): 161-165.

Gyles, C.L. 2008. Antimicrobial resistance in selected bacteria from poultry. Anim Health Res. Rev., 9,149-158.

Haque, A., Ahmed, J., Quereshi, A., 1999. Eaerly detection of typhoid by polymerase chain reaction. Ann. Saudi Med., 19(4): 337-340.

Hassan, M.M., Khaled, B.A., Ahaduzzaman, M.D., Mahabub, A., Shohel, A.F., Inkeyas, U., 2014. Antimicrobial resistance pattern against E. coli and Salmonella in layer poultry. Res. J. Vet. Practitioners, 2(2): 30 - 35. http://dx. doi. org/10. 20546/ijcmas. 2016. 507. 108

ISO 6579:2002. Microbiology-general guidance on methods for the detection of Salmonella, International Organization for Standardization, Geneva, Switzerlan.

Itoh, Y., Hirose, K., Miyake, M., Khan, A. Q., Hashimoto, Y., Ezaki, T., 1997. Amplification of rfbE and fliCgenes by PCR for identification and detection of Salmonella SerovarEnteritidis, Dublin and Gallinarum - Pullorum. Microbiol. Immunol., 41(10): 791-794.

Khan, A.A., Navaz, M.S., Khan, S.A., Cerniglia, C.E. 2000. Detection of multidrug resistant Salmonella Typhimurium DT104 by multiplex PCR. FEMS microbiol. Lett., 182, 355360.

Kiranmayi, B., Krishnaiah, N., 2010. Detection of Escherichia coli O157:H7 prevalence in foods of animal origin by cultural methods and PCR technique. Veterinary World, 3(1): 13-16.

Kruperman, P. H., 1983. Multiple antibiotic resistance indexing Escherichia coli to identity risk sources of faecal contamination of foods. Appl. Environ. Microbiol., 46, 165-170.

Loongyai, W., Benjamaporn, W., Naruemol, S., 2011. Detection of Salmonella and Escherichia Coli in Egg Shell and Egg Content from Different Housing Systems for Laying Hens. Int. J. Poultry Sci., 10(2): 93-97.

Luigi Ragni, Annachiara Berardinelli, Lucia Vannini, Chiara Montanari, Federico Sirri, Maria Elisabetta Guerzoni. and Adriano G., 2010. Non-thermal atmospheric gas plasma device for surface decontamination of shell eggs. J. Food Engineering, 100: 125-132.

Madhavaprasad, C.B. 2009. A comprehensive study on quality and safety of raw shell eggs from commercial layer farms and different markets, Ph. D. thesis. Maharashtra Animal and Fishery Sciences University, NAGPUR.

Makino, S., Kurazono, H., Chongsanguam, M., Hayashi, H., Cheun, H., Suzuki, S., Shirahata, T., 1999. Establishment of PCR system specific to Salmonella spp. and its application for the inspection of food and fecal samples. J. Vet. Med. Sci., 61(11): 1245-1247.

Malorny, B., Paccassoni, E., Fach, R., Bunge, C., Martin, A., Helmuth, R., 2004. Diagnostic Real-Time PCR for Detection of Salmonella in Food. Appl. Environ. Microbiol., 70(12): 70467052.

Manoj Jinu, R., Agarwal, K., Sailo, B., Wani, M. A., Ashok Kumar., Dhama, K., Singh, M. K., 2014. Comparison of PCR and conventional cultural method for detection of salmonella from poultry blood and faces. Asian J. Animal and veterinary $A d v .$, 9(11): 690-701. 
Martelli, F. and Daives, R. H., 2011. Salmonella serovars isolated from table eggs: an overview. Food Res Int., 45(2):745-54.

Masson, R. B. 1990. Recherche de nouveax disinfectants pour les produits de 4eme gamme, p. In Proc Congress Produits de 4eme Gammeet de 5eme Gamme. Centre for Education and Research for Food and Chemical Industries, Brussels, Belgium, pp. 101.

Musgrove, M. T., Jones, D. R., Northcutt, J. K. ., 2006. Antimicrobial resistance in Salmonella and Escherichia coli isolated from commercial shell eggs. Poult. Sci., 85(9): 1665-1669.

Nagappa, K., Shantanu Tamuly., Brajmadhuri.,Saxena, S. K., Singh, S. P., 2006. Isolation of Salmonella Typhimurium from poultry eggs and meat of Tarai region of Uttaranchal. Indian. J. Biotech., 6: 407-409.

Nicodim, F., Flore, C., George,N., Cosmina. 2011. Researches concerning the sensibility to neomycin of some bacterial strains isolated from chicken bulletin. UASVM, Vet. Med. 68(1): 1843-5270.

Oliveira, S. D., Santos, L. R. D., Schuch, M., Silva, A. B. C., Salle, T. P., Canal, C. W., 2002. Detection and identification of salmonellosis from poultry related samples. Vet. Microbiol., 87, 25-35.

Padron, M., 1995. Egg dipping in hydrogen peroxide solution to eliminate Salmonella Typhimurium from eggshell membranes. Avian Diseases, 39: 627 639.

Paul, N. F., Chah Kennedy and S. V. O. Shoyinka (2016). Molecular Detection of Salmonella Isolated from Poultry Farms in Abia State Southeast Nigeria, Int. J. Curr. Microbiol. App. Sci 5(7): 961-968

Pui, C. F., Wong, W. C., Chai, L. C., Tanung, R., Jayaletchumi, P., Noor Hidayah, M.
S., Ubong, A. Fariznaleen, M. G., Cheah, Y. K., Son, R., 2011. Salmonella: A foodborne pathogen. Int Food Res. J., 18, 465-473.

Rahman, H., 2002. Some aspects of molecular epidemiology and characteristics of Salmonella Typhimurium isolated from man and animals. Indian J. Med. Res., 115, 108-112.

Rahn, K. S. A. De Grandis, R. C., Clarke, R., Curtiss, Gyles, C.L. 1992. Amplification of invA gene sequence of Salmonella typhimurium by polymerase chain reaction as a specific method of detection of Salmonella. Mol. Cell. Probes, 6: 271-279.

Safaei, H.G., Mohammad, J., Ahad, H., Tahmineh, N., Ali, S., Ebrahim, R., 2011. The prevalence of bacterial contamination of table eggs from retails markets by Salmonella spp., Listeria monocytogenes, Campylobacter jejuni and Escherichia coli in Shahrekord, Iran Jundishapur. J. Microbiol., 4(4): 249253.

Sella, B.R., Belquis, P., Guizelinand Hindy, R. 2012. Validation of peracetic acid as a sporicide for sterilization of working surfaces in biological safety cabinets. $J$. Microbiol. Infectious Dis., 2(3): 93-99.

Singh, M., Chaudhry, Y., Sanyal, S.C. 1992. The spectrum of antibiotic resistance in human and veterinary isolates of Escherichia coli to collected from 198486 in Northern India. J. Antimicrobial. Chemother., 29: 159-168.

Smith, H.W. and Hall, S. 1966. Observations on infective drug resistance in Britain. Vet. Rec., 78, 415-424.

Sreenivasaiah, P. V.,2006. Scientific Poultry Production: A Unique Encyclopaedia ( $1^{\text {st }}$ d, pp 454. ). International Book Distributing Co.

Sudhaharan, S., Padmaja, K., Solanki, R., Lakshmi, V. Umabala, P., 2014. Extraintestinal salmonellosis in a tertiary care 
center in South India. J. Infect. Dev. Ctries. 8(7): 831-837.

Whistler, P. E. and Sheldon, B. W., 1988. Bactericidal activity, eggshell conductance, and hatchability effects of ozone versus formaldehyde disinfection. Poultry Sci., 68:1074-1077.

Wolffs, P. F., Glencross, K., Thibaudeu, R., Griffithd, M. W., 2006. Direct quantitation and detection of Salmonellae in biological samples without enrichment, using two step twostep filtration and real time PCR. Appl. Environ. Microbiol., 72(6): 3896-3900.
Woo, P. C. Y., Fung, A. M. Y., Wong, S. S. Y., Tsoi, H. W., Yen, K. Y., 2001. Isolation and characterization of a Salmonella enterica serotype Typhi variant and its clinical and public health implications. J. Clin. Microbiol., 39(3): $1190-1194$.

Zahrei, S. T., Mahzounish, M., Saeedzadeh, 2005. The isolation of antibiotic resistant Salmonella from intestine and liver of poultry in Shiraz province of Iran. Int. J. Poult. Sci., 4(5): 320-322.

\section{How to cite this article:}

Vinayananda, C.O., Mohamed Nadeem Fairoze, C.B. Madhavaprasad, S.M. Byre Gowda, C.S. Nagaraj and Nagappa Karabasanavar. 2017. Studies on Occurrence, Antibiogram and Decontamination of Salmonella enterica in Table Eggs. Int.J.Curr.Microbiol.App.Sci. 6(3): 2163-2175. doi: https://doi.org/10.20546/ijcmas.2017.603.247 